\title{
THE FASCIOCUTANEOUS FLAP: IT'S USE IN SOFT TISSUE DEFECTS OF THE LOWER LEG
}

\author{
MD. SHAMSUZZAMAN ${ }^{1}$, MD. ISRAR KAMAL ${ }^{2}$, MD. MASOOM $^{3}$, MD. ANOWARUL ISLAM $^{4}$
}

The fasciocutaneous flap is very useful in the repair of soft tissue defects on the lower leg. It is easy to design and construct large flaps that are safe because of the good circulation. The operating time is short for an experienced surgeon and no extra equipment is needed. It is perfectly possible to carry out surgery on the underlying bones at the same time. The postoperative treatment is simple for both the patient and the staff. The surgical technique is described and the result of 23 flaps are critically reviewed.

Skin defects below the knee present difficult problems particularly when combined with fractures, pseudarthrosis, osteitis, osteomyelitis and so forth. The pioneers of plastic surgery soon found that a flap of acceptable proportions that easily survived elsewhere on the body became necrotic on the lower leg. For several decades, most text books have advised against the use of local flaps below the knee. In some texts this same warning is given indirectly, the book showing many illustrations and drawings of local flaps on every part of the body except the lower leg.

It is true that in selected cases it is possible to use local flaps after delay incisions or when adopting special techniques. However this methods may give good results in experienced hands but the disadvantages of these methods are well known. Today, a free flap transfer can give a good result but the technique calls for a trained team, expensive instruments and plenty of time. Muscle flaps or myocutaneous flaps have been used very successfully in reconstructions all over the body but present serious difficulties in the lower leg where the muscles are very thin and even with careful dissection adequate cover may be almost impossible to achieve.

\section{The fasciocutaneous Flap:}

This paper presents a new type of the local flap the fasciocutaneous flap, which includes the skin, the

1. Associate Professor, Ortho-Surgery, Dhaka Medical College, Dhaka

2. Registrar, Ortho-Surgery, DMCH

3. Registrar, Ortho-Surgery, DMCH

4. Resident, Ortho-Surgery, DMCH subcutaneous fat and the fascia but not the muscle. This flap can be used from the level of the knee down to the foot and there are no problem in designing a flap measuring $18 \times 18 \mathrm{~cm}$ or of even more unfavorable proportions.

When making incisions into the muscle compartments of the leg it is very easy to carry out a blunt dissection in the cleavage plane between the fascia and the muscle with minimal bleeding. It can also be demonstrated clinically that large muscle can be used whatsoever with the circulation and nutrition of the remaining overlying fascia, fat and skin. This implies that the most important vessels from the muscle through the fascia into the fat and skin penetrate the fascia proximally. The studies of Daniel and Williams (1973) show that the vascular arrangement follows the axis of an extremity. Two types of artery from these muscular perforating brahches supply the skin (I) musculocutaneous vessels that supply a relatively small area of skin (2) direct cutaneous vessels that run parallel to the skin immediately about the muscle and fascia and are usually accompanied by two venae comitantes, an observation made by Webster as long ago as 1937 . When raising a fasciocutaneous flap these important vessels are always included and a good arterial and venous circulation is assured. Indeed, according to Schjelderup (1979), Gillies advised his pupil to include at least part of the underlying fascia. Mc Gragor (1975) pointed out that the deltopectoral flap can be extended if the fascia is included in flap. In their dissection studies Mathes and Nahi (1979) found that, for instance the musculocutaneous perforators from the skin distal to the muscular portion and over the Achilles tendon. The tensor-fasciae-latae flap described by Nahai et al. (1978) demonstrates a similar and even more striking arrangement with single proximal vascular pedicle. 


\section{Surgical technique:}

Before rotating the flap the defect to be covered should be revised and if possible reduced in size with the aid of split skin grafts. In many of these cases it may be necessary in conjunction with the orthpaedic surgeons to chisel off bone, remove squestra and occasionally insert a bone graft.

The flap is planned in the usual way with the base always sited proximally. The incision is carried right through the skin, subcutaneous tissue and fascia: a couple of sutures or hooks in the fascial margin can then be used to hold the flap. The dissertation is best carried out from one of the long incisions and the surgeon should avoid damaging the delicate and often thin layer of loose connective tissue between the fascia and the underlying structures. This tissue should be left undisturbed. It has a rich vascular supply, provides a good base for a split-skin graft and can also very quickly produce a layer of healthy granulation tissue. The more proximal the dissection the more care should be taken to avoid cutting the perforators supplying the flap. Neddless to say it is always good practice to include one of the saphenous veins, if possible, in the design of the flap.

In my experience the fascia is a rather tough structure and tends to hinder rotation of the flap and a proximal back cut though the fasia is of terned necessary. This must be made with the utmost care to avoid severing the supplying vessels. The flap can now be rotated without any difficulty.

The skin surrounding the defect is then excised and the edges of the wound undermined. The fasciocutaneous flap is rotated into position and the fascia is sutured beneath the undermined skin. Only a few tacking sutures are needed to keep the flap in place: fine sutures are used to coapt the skin edges.

When rotating very large flaps a "pig's ear" is unavoidable and should be left for correction later. The secondary defect can be covered immediately with a split-skin graft. However, the surface is usually irregular and I often prefer to cover with granulation tissue which provides an even surface which as a "pseudofascia". An immediate skin graft may be taken perfectly but bleeding under the skin graft is not uncommon and then the take will be only partial. When grafting the defect after 10-15 days there is a better take. The area is bandaged with moderate pressure and if possible the distal part of the flap is left open for inspection. If bleeding is troublesome continuous suction drainage can be used for 24 hours or more.

This is a very simple operation and a short one when performed by an experienced surgeon, Postoperatively the patient can be in his wheel-chair the next day provided the foot and leg are kept in a horizontal position.

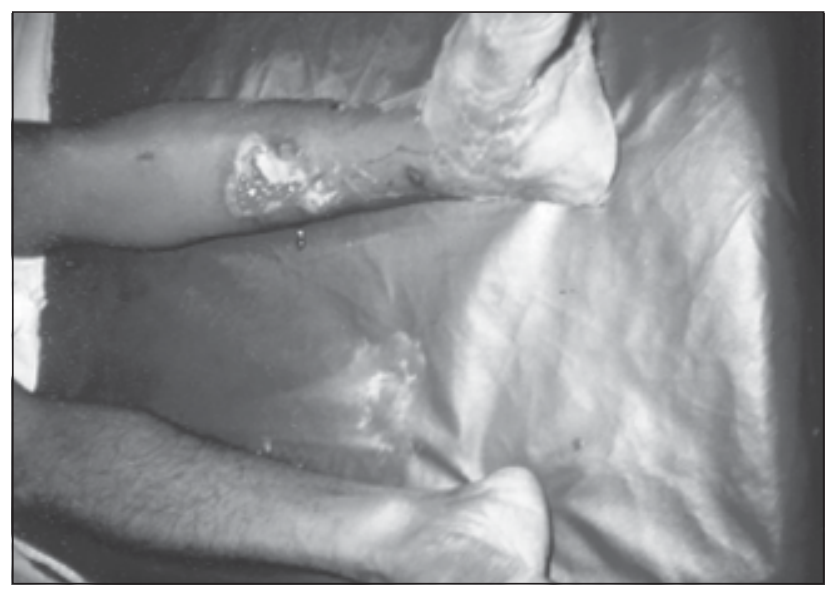

Fig. 1: Shows Gustillo IIIB injury of the left leg

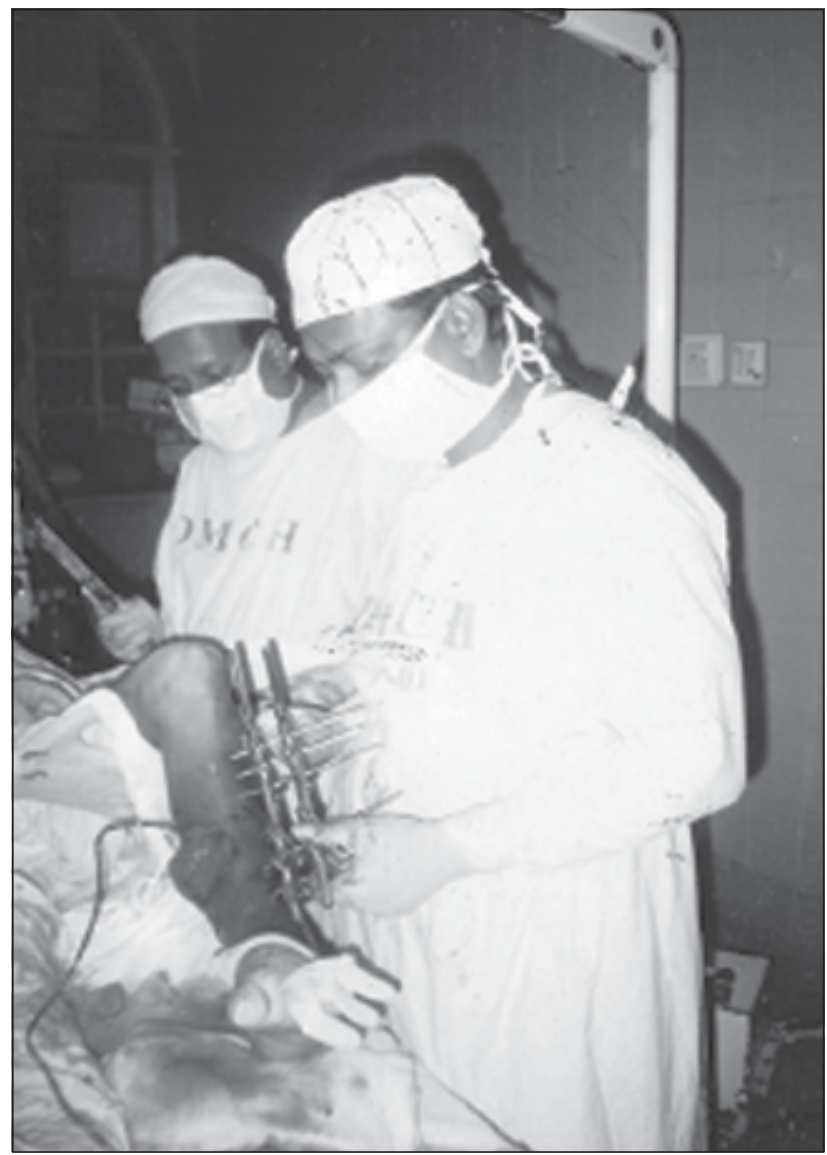

Fig.-2: After stabilization of fracture by external fixator 


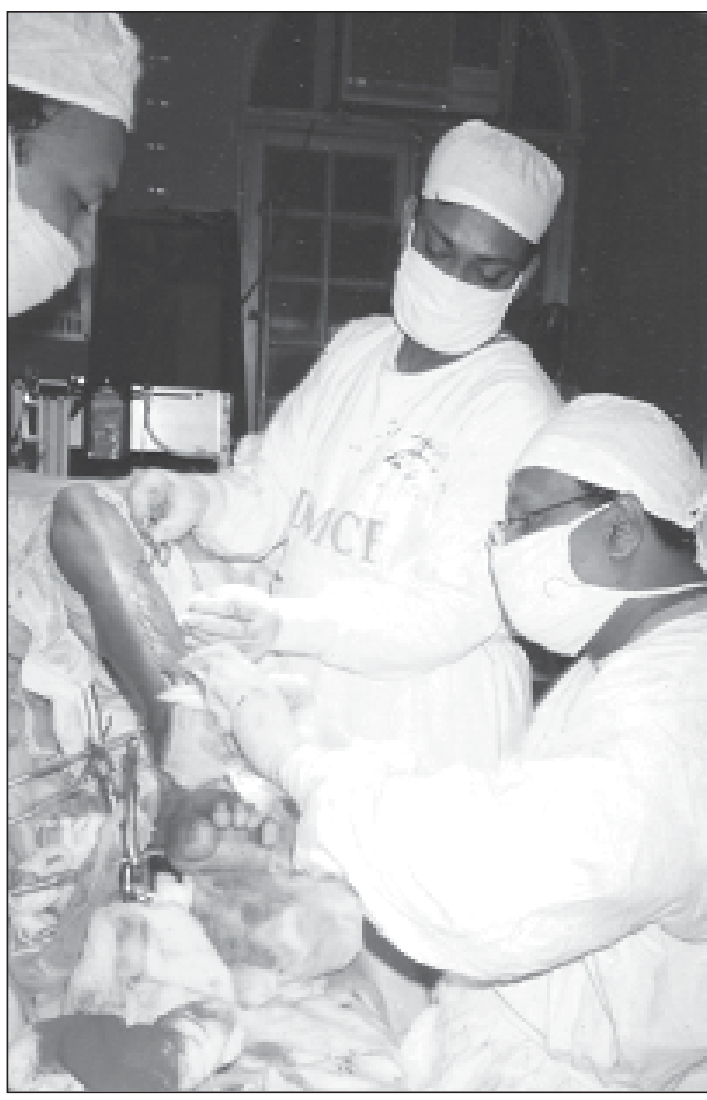

Fig. 3: After flap coverage of open wound

\section{Clinical Observation;}

During the period 1995 to 2002 this technique has been used for 23 flaps in 22 patients. Only two patient were women. The youngest patients was 15 , the oldest 71, the average age being 42 years, 6 patients were 60 years or older.

Four defects to be covered were on the proximal third of the lower leg. 8 on the middle third and 11 on the distal part of the leg. The shortest flap was 6 $\mathrm{cm}$, the longest $22 \mathrm{~cm}$. Out of the 23 were $15 \mathrm{~cm}$ of longer. The base varied from 3 to $10 \mathrm{~cm}$ and the proportion of the "average flap" was $15 \times 6 \mathrm{~cm}$ that is $2.5: 1$.

Fourteen of the flaps were designed on and rotated from the lateral side, six from the medial side, two from the posterior side and one from the dorsum of the foot.

These patients usually presented a combination of problems. In addition to the soft tissue defect there were unhealed, recent or old, fractures or peudrathrosis in 16 cases. Many wounds ware infected with osteitis and osteomyelitis with or with out sequestrum. In four cases there were scars, ulcers or fistulae after old injuries; two patients presented with defects after earlier surgery measures are required and the same time as the flap necessary to chisel off devitalized bone or to remove sequestra.

\section{Result:}

There were three failures (Table- I). A 70 years old man became confused a few hours after surgery and he was found walking around in the ward. The sutures cut through and the flap swung back by it self.

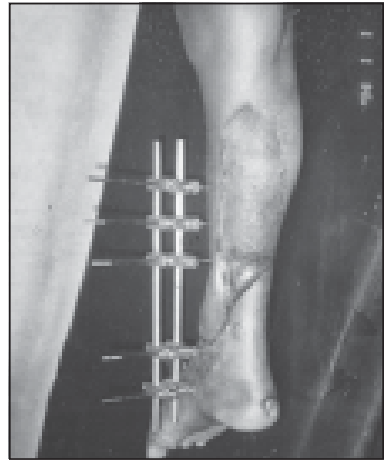

Fig.-4: Follow up after three weeks

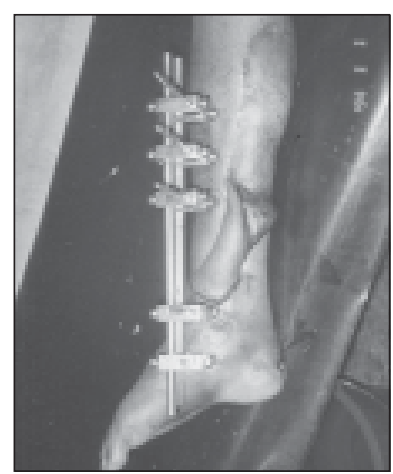

Fig.-5: Follow up after three months
Table- I

The result in 23 fascioeuteous flaps.

\begin{tabular}{lll}
\hline Failures & - & 3 \\
Fair & - & 3 \\
Good & - & 17 \\
\hline Total & 23 \\
\hline
\end{tabular}

In another case, a wound infection was aggravated by the flap repair. About $50 \%$ of the flap was lost and the rest had to be returned to its base.

The third patients, following a serious crush injury, open fractures. The injury and earlier surgery had left several deep scars surrounding the actual defect. Part of the fasciocutaneous flap was lost due to infection from the bone underneath but even if this case is recorded as a failure the patient was actually better of when the healing eventually took place.

In three cases the results were fair due to loss of the tip of the flap. The damage was always superficial and when the necrotic skin was excised there was viable vital fat and fascia underneath. Granulation tissue formed quickly and all defects were successfully grafted. The largest area lost is illustrated in figures. 
In 17 cases the flap healed completely. When related to the large areas to be covered and the complicating problems these good results are impressive. It is only fair to add that when judging the results I have only taken into consideration the circulation and the healing of the flap. In some case there were other complications such as bone infections and fistulae developing several weeks later.

\section{Conclusion:}

My experience with 23 fasciocutaneous flaps has convinced me that this maneuver should always be considered when one in faced with the problem of covering a soft tissue defect on the lower leg. The alternatives are to use a myocutaneous flap proximally and a free flap distally. The advantages of the fasiocutaneous flap are obvious and when in doubt it is wise to remember O Brien's (1978) advice to use the simplest procedure that will provide adequate cover. Comparing the free flap with a local skin flap he pointed out that a local flap is much simpler, requires less time and involves less risk to the patient.

\section{Reference:}

1. Daniel, R. K and Williams, H.B (1973). The free transfer of skin flaps by microvascular anastomosis, Journal of Plastic and Reconstructiove Surgery, 52,16 .

2. Nahai F, Silverton. J.S Hill H.L and vasconez L.O (1978). The rensor fasciae latae musculocutaneous flap. Annals of Plastic Surgery, 1, 372.

3. Mathes S.J and Nahai F (1979). Clinical Atlas of Muscle and Musculocutaneous Flaps. St. Louis CV, Mosby Company.

4. O Brien, B McC, and Hayhurst, JW (1977). Principles and rechniques o fmicrovascular surgery. In Reconstrauctive Plastic Surgery. Philadelphia, Edited by JM Converse. Vol. 1, Chapter 14, W.B saunders Company.

5. Strak RB, (1962), Plastic surgery, New York, Harper and Row.

6. Webster J. P. (1937), Thoraco-epigastric tubed pedicles. Surgical Clinics of North America. 17, 145. 